\title{
Discriminant Analysis of Chronic Malnutrition During Early Childhood in E Province Kwango (2013-2014)
}

\author{
Cush Ngonzo Luwesi*1, Jospin Kapende Kilembe ${ }^{2}$, Zacharie Kibanda Kidiatata² and Mitondo Kiese ${ }^{2}$ \\ ${ }^{1}$ Associate Professor, Faculty of Science Ekonomi that century, Democratic Republic of the Congo \\ ${ }^{2}$ Wizard, Institute Superior des techniques Medical Mary Queen of Peace Kenge (ISTM-MRP), Democratic Republic of the Congo \\ *Corresponding author: Cush Ngonzo Luwesi, Associate Professor, Faculty of Science Ekonomi that century, Kenge, Democratic \\ Republic of the Congo
}

\section{ARTICLE INFO}

Received: 㓞 May 06, 2019

Published: 蔧 May 15, 2019

Citation: Cush Ngonzo L, Jospin Kapende K, Zacharie Kibanda K, Mitondo K. Discriminant Analysis of Chronic Malnutrition During Early Childhood in E Province Kwango (2013-2014). Biomed J Sci \& Tech Res 18(1)-2019. BJSTR. MS.ID.003097.

\begin{abstract}
The prevalence of malnutrition during childhood or infancy small (the period under 5 years old or from 0 to 59 months) in the DRC is Likely to be Significantly Higher Than the natural limit. This study aims to identify the main determinant of chronic malnutrition among small children of 0 - 59 months in the province of the Kwango $\mathrm{T}$ is discrimination which is used factor has analysis of data from the demographic and health survey (ED S - CRD II). This analysis encompassed a description of the sample data, qui enabled a correlational analysis of the factors related to chronic malnutrition, and a multivariate discrimination of the Most Significant factors based binary logistic regression was (logit). The results indicate that chronic malnutrition in the Kwango province is likely to be due to the lack of multisectoral strategies appropriate to the fight against chronic malnutrition. This global growth retardation (GFR) of children and their development is also attributable to socio-cultural aspects such as poverty, lack of latrines and the number of children in the household, as well as the level of education and the age of mothers. . The study recommended an integrated, multi-sectoral approach to implementing interventions to eradicate chronic malnutrition among stunted young children in Kwango Province.
\end{abstract}

Keywords: Chronic Malnutrition; Crude Growth Retardation (CGR); Discriminate or Multivariate E Analysis; Small Childhood or Infancy

\section{Introduction}

Prevalence of chronic malnutrition among small children (those under 5 years old or from 0 to 59 months ) in the DRC would be significantly higher than the natural threshold. The purpose of this study was to identify the main determinants of chronic malnutrition in small children in Kwango Province based on discriminant factor analysis of Demographic and Health Survey data (DHS-DRC II). It consisted of a descriptive analysis of the sample, followed by correlational analysis was fact $\mathrm{r}$ s related to chronic malnutrition, and discrimination which is io $\mathrm{n}$ Multivariate of the most significat yew factors by binary logistic regression (LOGIT). The results indicate that chronic malnutrition in Kwango Province is primarily due to lack of multisectoral strategies appropriate to the fight against chronic malnutrition. This global growth retardation (GFR) of children and their development is also attributable to socio-cultural aspects such as poverty, lack of latrines and the number of children under 5 in the household, as well as the level of instruction and the age of mothers. The study recommended an integrated, multi-sectoral approach to implementing interventions to eradicate chronic malnutrition among stunted young children in Kwango Province. The malnutrition represents at least $45 \%$ of infant mortality in the world, and more 165 million children worldwide experiencing an overall growth retardation (RCG) was due to chronic malnutrition, don 4 40\% of NEET in vi the Sub-Saharan Africa [1,2]. According to the Lancet Series (June 2013 ), malnutrition is responsible for $45 \%$ of deaths among are the children under 5 years in the DRC. This infant island mortality is mainly due to diseases that are preventable through simple and inexpensive measures of prevention or treatment that parents can take [3,4]. In fact, each year more than two million children under five in the world suffer from severe acute malnutrition. More worrying still, over 6 
million children in the same age group suffer from stunted growth due to chronic malnutrition, a form of malnutrition long ignored while s are devastating consequences [5].

Malnutrition Est multifactorial and requires a multisectoral response, including the change of $s$ behavior and the evolution of social norms [6]. Nutritionally, a transition from emergency programs and management of acute malnutrition to a prevention program is $\mathrm{n}$ écess area [7,8]. For preventive activities, DRC currently puts more emphasis on revitalizing the Preschool Consultation (SPC) and the Nutrition Assisi Community (NAC) with a focus on interventions based on the window of opportunity of the $1000 \mathrm{~s}$ first days, that is, the period from conception to birth until age $2[9,10]$ These interventions are carried out both in the health structures and in the communities with their own participation. It is therefore crucial and urgent to recognize that chronic malnutrition has frightening consequences both for the child's productivity and for the economic development of all communities. living in Kwango Province. It is perpetuated from generation to generation and can compromise the harmonious development and success in the lives of young people in the province [11]. Thus, it is imperious to invest now in the eradication of this scourge to enable these young people to flourish in life. But q ue ls factors $\mathrm{s} t$ is crucial in the spread of chronic malnutrition since early childhood in the Kwango ? And that they measure the Kwangolaise s authorities can they take to eradicate this scourge in joung children under 5 years? Cetteonc study intends to identify the determinants of chronic malnutrition in children under 5 in the new Province of Kwango to better prioritize interventions. Specifically, this study aims to establish a relationship between socio-demographic, sociocultural and stunting characteristics among children aged 0-59 months in Kwango; and determine the prevalence of chronic malnutrition in children 0-59 months of age according to their demographic, nutritional, health, environmental and sociocultural characteristics.

\section{Review of the Literature}

The prevalence of malnutrition is very worrying in the world but especially in Africa, where it has not changed in the last ten years. Chronic malnutrition affects 165 million children worldwide , compared to $40 \%$ in sub-Saharan Africa. Malnutrition Est at the base of at least $45 \%$ of infant mortality in Africa [12]. L chronic malnutrition before the age of two is insidious and silent but has devastating consequences for the individual, the community and the nation. In fact, most areas affected by chronic malnutrition are considered to be the granaries of their provinces. These areas export crop products outward while they experience nutritional crises. So , Chronic malnutrition causes about an annual loss of 2 to $3 \%$ of Gross Domestic Product (GDP), j being and all life and its livelihood on quicksand $[13,14]$. In addition, the chnt known among other compromise cognitive development, learning skills diminished, poor school performance, and in adulthood, reduced productivity. An adult who has suffered from chronic malnutrition as a child earns about $20 \%$ less than an adult who has not suffered from this form of malnutrition [15]. The DRC is not immune to this scourge, which has become a serious public health problem.

Indeed, the analysis carried profile e in 2007 showed that malnutrition is the underlying cause of half of all deaths. DRC ranks eighth in the list of countries with the highest number of stunted children. It is one of only three countries that alone account for $40 \%$ of all deaths of children under five [16-18]. This mortality set so $u$ has the highest world, even though heist bay slightly e past five years. According DRC (2014), the infant mortality rate e n DRC suite around of 58 miles (58\%) while the child mortality rate is 104 per thousand $(104 \%$ o). These data from the E NQUIRY émographique D and $S$ ante (EDS) 2013-2014 peninsula indicate that a child under five in ten suffers from emaciation (8\%); one in two is stunted $(43 \%)$, and one in five is underweight (23\%). Moreover, the results of surveys s MICS 2010 indicates that one in three households is food insecure. The present province of Kwango , which comes from the former province of Bandundu, is no exception to this situation that the rest has negative consequences throughout the life of the child, public health, the e NOMIC and development communities [19-21].

Like the country, the proportion of under-five children suffering from chronic malnutrition in the former Bandundu in general and in Kwango is in full progression, reveals the DHS 2013-2014 . It went from $32 \%$ in 2010 to $39.2 \%$ in 2014 . In the new province of Kwango , the prevalence of chronic malnutrition is around $45,6 \%$, exceeding the national average [21-23]. Among children who reach the first 1000 days, this prevalence is greater than $50 \%$. In absolute numbers, the number of children under 5 suffering from chronic malnutrition represents more than 220,000 children ( DRC,2014). The prevalence of acute malnutrition in the province Kwango also remains preoccupied $\mathrm{n} \mathrm{t}$ e that chronic malnutrition with a rate of $11,6 \%$, which beyond the emergency threshold of $10 \%$. These proportions are much higher s compared to what is expected of a population in good health and well fed ed, namely $2.3 \%$ to -2 standard deviations s and $0.1 \%$ to -3 standard deviations [2426]. Ell es are even astronomical, pasts often unnoticed, mainly because that is not always e st knowledgeable and convinced the consequences of malnutrition. The DRC in its fight against malnutrition effort has made a lot of effort $s$ in the healthcare sector. But day, it is clear that direct nutrition interventions in the health sector alone provide $20 \%$ of the solution. Ince and more than a year, more than one health area Kwango years l e st nutritional alert [27-30]. This resurgence of malnutrition in the Kwango shows that the only management of acute malnutrition cases in the s centers $\mathrm{n}$ nels utrition, without being associated with other activities sect or ial s, has limitations proven. Accelerating the reduction of various forms of malnutrition among vulnerable groups therefore requires the involvement of so-called nutrition-sensitive sectors. Hence the need to reflect on multisectoral mechanisms to combat malnutrition [5,8]. Recognizing this, the DRC has a national nutrition policy and e September 2015. In addition to the health 
sector, it gives prominence to nutrition-sensitive sectors, including agriculture, health and sanitation, education, gender and family , as well as social protection.

\section{Materials and Methods}

\section{Description of the Study Environment}

This study was conducted in the new Province Kwango created by the 2010 Constitution (DRC 2010). A triangulation of data from the administrative census of the City of Kenge (2017) and MINIPLAN ( 2016 ) indicates that this province covers an area of $126,918 \mathrm{~km} 2$ with a total population estimated at 4,893,960 inhabitants in 2014 and therefore a density of 38,56 inhabitants / Km 2. the Province is limited to the north by the Wamba River and $\mathrm{Z}$ one of Health of Kikongo; to the south by the full Makiosi and the Kimbau ZS ; to the east by the river and the Z Inzia one of $\mathrm{H}$ ealth of Masi- Manimba; in the West, by the Wamba River and one of Z Health Boko. The national road N 1 (Kinshasa-Kikwit), 275 km long, is the main channel of communi cation of the province. The climate is tropical wet with two seasons plu v ie uses (September - January; and Mars-May) and two dry seasons (May to September; January-March) . This partly explains the presence of the woodland savannah. The city is entirely on plateau intersected by valleys, and sometimes, hills between the rivers Wamba in the west and Bakili in the east. The Kenge soil is sandy Karoo-Kalahari type. Its vegetation consists essentially of grassy savannahs, woodlands and forest galleries found along the rivers.

The population of Kenge is $80 \%$ rural and agro-pastoral activities nt $\mathrm{s}$ is the main source of income. Trading companies also offer Employment da $\mathrm{n}$ s the areas of trade, small and medium business , motorcycle $t$ axis as well as education, health and public administration. This population $\mathrm{t}$ e s essentially from the Yaka ethnic group but can be cosmopolitan in urban areas. It includes the population's ethnic and tribal Yaka Pelende, Mbala, Suku, Hungani, Kongo, N gala, Swahili and phones. L Pelende tribe is more predominant in the town of Kenge.

Known as the main granary of the capital Kinshasa, the Kwango Province has a huge agricultural potential with varied and rich cultures. But however, 1 in 2 children in the Kwango suffers from chronic malnutrition. This disease is the basis, in the child of compromised cognitive development, diminished learning skills, poor academic performance, and in adulthood, reduced productivity. Changing this situation is possible with the commitment of all.

\section{Sampling Method and Data Collection Technique}

This study is documentary and retrospective, using the document analysis method based on data from the Demographic and Health Survey (DHS-DRC II 2013-2014), a national crosssectional survey conducted by the Ministries of Planning. and Health between the end of November 2013 and the beginning of February 2014 on the situation of children and women (DRC, 2014). The population is made up of all children aged 0 to 59 months with chronic malnutrition during the above-mentioned period. The sample of the ETUD e a and e first drawn in a way to latoire and then a selection was made so as not to bring out the children of the province of Kwango aged 0-59 months, who had symptoms of chronic malnutrition at the time of the survey.

\section{Data Analysis Techniques}

This study uses a multivariate discriminant analysis of data from the demographic and health survey (EDS-DRC II). The approach Consist e a descriptive analysis of the sample, which i s a perm correlational analysis of factors related to chronic malnutrition and multivariate discrimination of the most significant factors by binary logistic regression (logit) in order to establish a relationship between the sociocultural characteristics of the sample and growth retardation in children 0-59 months of a Province u Kwango. To describe the population of malnourished children surveyed, the study used the absolute frequencies are century and relating to determine the prevalence of chronic malnutrition among children are c. The data has been tabulated to facilitate the calculation of frequencies based on the following formula:

\section{$\mathrm{f}=\mathrm{Fo} / \mathrm{FA}^{*} 100 \quad$ [Equation 1]}

$\mathrm{f}=$ Relative frequency

$\mathrm{FO}=$ Frequency observed

$\mathrm{FA}=$ Expected frequency

For (Table 1) correlation between the nutritional status of children aged 0-59 months (RCG or N on - RCG) and sociodemographic and cultural characteristics of households are, the Khi-Carré statistics ( $\mathrm{Khi}^{2}$ or $\mathrm{Q} 2$ ) was tested at the $5 \%$ significance level $(p=0.05)$. What helped in validating, in some cases, the null hypothesis that there was no relat ion e $n$ tre the expected distribution of the nutritional status of children aged 0-59 months (E) and observed that e da ns alleged demographic and sociocultural factors explain this social Nutritional status of children (0). Thus, the century following assumptions have been testing:

Table 1: Distribution of respondents according to their demographic characteristics.

\begin{tabular}{|c|c|c|c|}
\hline Feature & Value & Effective & Percentage \\
\hline Sex & $\begin{array}{c}\text { Female } \\
\text { Male }\end{array}$ & 190 & 49 \\
& 198 & 51 \\
\hline age range & $\begin{array}{c}\text { Less than 24 months } \\
\text { 24 months and over }\end{array}$ & 160 & 41.2 \\
\hline $\begin{array}{c}\text { Number of children } \\
\text { less than 5 years }\end{array}$ & $\begin{array}{c}\text { Less than 5 } \\
\text { 5 years }\end{array}$ & 245 & 68.8 \\
\hline \multirow{2}{*}{ Household size } & $\begin{array}{c}\text { 0- 7 people 7 people } \\
\text { and more }\end{array}$ & 185 & 36.9 \\
\hline Marital status \\
mothers & $\begin{array}{c}\text { Lives alone } \\
\text { Live in union }\end{array}$ & 342 & 203 \\
\hline
\end{tabular}

$\mathrm{H}_{0}: \mathrm{E} \neq \mathrm{O}$, there is a significant difference entre distributions of E and 0 
$\mathrm{H}_{1} \mathrm{E}=\mathrm{O}$, There not significant difference between the $\mathrm{E}$ and $\mathrm{W}$ of distributions

Where,

$E_{i}$, the $i^{\text {th }}$ expected size of the nutritional status of children aged 0-59 months in households

$\mathrm{O}_{\mathrm{i}}$, the $\mathrm{j}^{\text {th }}$ observed effective da ns the distribution of demographic and socio-cultural socio

$\mathrm{ddl}$, the degree of freedom (equal to $\mathrm{nk}$ )

$\mathrm{n}$, the total number of the sample

$\mathrm{k}$, the number of estimated parameters (equal to the number of factors)

p, the signi fi cation rate (equal to the probability of failure of Ho )

Finally, multivariate discriminant analysis was used to de finished first the most significant predictors of the nutritional status of children in the Province of Kwango. Given the dichotomous nature of the dependent variable on the one hand and the purpose of the study on the other hand, we used the binary logistic regression model (LOGIT) represented by the following formula (Equation 3):

$Y i=\alpha i j+\beta 1 j \times 1 j+\beta 2 j \times 2 j+\beta 3 j \times 3 j+\beta 4 j \times 4 j+\varepsilon i[$ Equation 3]

Where,

$\mathrm{Y} \mathrm{i}$, is the nutritional status of children from 0-59 months : RCG or Non-RCG (normal)

$\mathrm{X}$ ij are the demographic and socio-cultural socio supposed character é riser nutritional status of children, including the got the household $\left(x^{1}\right)$, the GE to the mother $\left(x^{2}\right)$, the e marital status $\left(x^{3}\right)$, the level of instruction $\left(x^{4}\right)$, the wealth index $\left(x^{5}\right)$, the source of drinking water $\left(x^{6}\right)$, the $t$ ype of latrines $\left(x^{7}\right)$, etc.

$\alpha \mathrm{ij}$ is the intercept or the constant e of the model

$\beta$ ij are the regression coefficients attached to each $s$ are independent variable.

This model has the advantage of providing the net effect of each independent variable in the determination of the nutritional status of malnourished children are interviewed in the presence of others. $\mathrm{C}$ and allowing derive $\mathrm{r}$ subset of preventive factors that explain the vulnerability of children in the DRC. The latter is estimated on the basis of the risk or the probability of occurrence of the RCG modality when the child is declared malnourished (Child 0-59 months with RCG) and the non-occurrence of the RCG modality (Child i of 0 - 59 months normal). It should be noted that prior to this analysis, the data collected in the database DHS-RDC II 2013-2014 were first prétraitées, and this operation consisted in the creation of another database containing essentially the variables used below concerning only the children are 0-59 month living in Kwango Province.

\section{Results and Discussion}

\section{Sociocultural and Demographic Status of S Little Children and Their Mothers}

Table 1 indicate that e $\mathrm{n} \mathrm{s}$ ghost male dominates the sample ( $51 \%$ co $n$ be $49 \%$ for girls are. The majority of the mothers have more children under 24 months (58.8\%) compared to those aged at least 24 months $(41.2 \%)$, children under 5 years retrouv year $t$ dan s $63.1 \%$ of households are. According to u even table that more than half of households have a size of at least 7 people ( $52.3 \%$ ) . Regarding the marital status of mothers of children, 9 out of 10 mothers live in union with their husbands. Of the 191 children, $77.5 \%$ had received the first breast milk in the hour after birth. Its children had been placed in immediately after Bachelor childbirth to receive colostrum while $22.5 \% \mathrm{n}$ had not benefited immediately (Table 2). The analysis also reveals that one child under five years of 2 (45.9\%) suffering from chronic malnutrition in the province Kwango. The size-for-age index is below -3 standard deviations from the median of the reference population. These proportions are considerably higher compared to those that are expected to find in a population re healthy and well nourished, namely $2.3 \%$ -2 standard deviations and 0.1\% -3 standard deviations. As for the quality of water sources and sanitation in the province Kwango, Table 3 shows that almost every household uses nt the water source x s undeveloped (99.2\%), a on the other hand, three- quarters of households use unhygienic trins (75.8\%).

Table 2: Parameters nutrition of children from 0 to 59 month.

\begin{tabular}{|c|c|c|c|}
\hline Parameter & Value & Effective & Percentage \\
\hline \multirow{2}{*}{$\begin{array}{c}\text { Breastfeeding after } \\
\text { childbirth }\end{array}$} & After hour & 43 & 22.5 \\
& In the hour & 148 & 77.5 \\
& Total & 191 & 100 \\
\hline \multirow{2}{*}{ Nutritional status } & Good condition & 210 & 54.1 \\
& Trowth retardation & 178 & 45.9 \\
& Total & 388 & 100 \\
\hline
\end{tabular}

Table 3: Qualities of water and toiler facilities is utilized by households.

\begin{tabular}{|c|c|c|c|}
\hline Feature & Value & Numbers & Percentage \\
\hline $\begin{array}{c}\text { Sources of } \\
\text { drinking water }\end{array}$ & Unmanaged & 385 & 99.2 \\
\hline \multirow{2}{*}{ Latrine types } & fitted & 3 & 0.8 \\
\hline Total & Hygienic latrine & 94 & 75.8 \\
\hline
\end{tabular}

Tables $3 \& 4$ has u Figure 1 shows the distribution of mothers of children aged 0-59 months according to their socio-cultural characteristics, including educational attainment and wealth index. The analysis of indi education that only three mothers -dixième $e$ s t-school (31.8\%) while the majority of mothers has some form of education (68.2\%). But in terms of the wealth index, pre s e d $70 \%$ of mothers living in the EC s euil poverty. That does not surprise anyone for a province that is almost devoid of all economic infrastructures. 


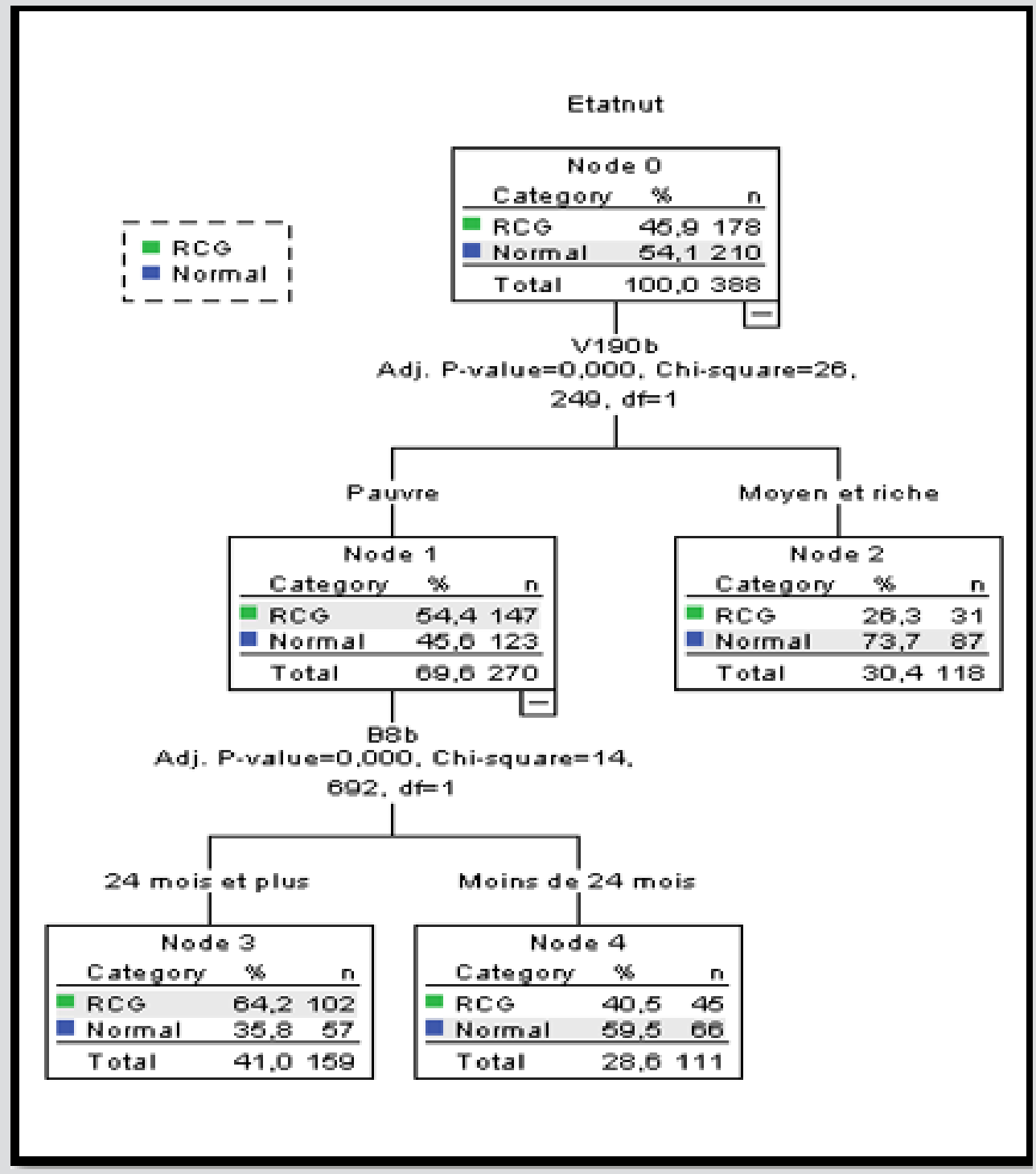

Figure 1: Classification of VARIAbles by nUtRItional StATUS OF CHILDREN.

Table 4: Characteristics sociocultural mothers of small children are uenq.

\begin{tabular}{|c|c|c|c|}
\hline Feature & Value & Effective & Percent (\%) \\
\hline \multirow{2}{*}{ Level of education } & \multirow{2}{*}{ No level educated } & 119 & 31.8 \\
& & 255 & 68.2 \\
\hline \multirow{2}{*}{ Wealth index } & Poor & 270 & 270 \\
& Middle and rich & 118 & 118 \\
\hline Total & & 388 & 100 \\
\hline
\end{tabular}

Correlation Between the Status Small Children and Chronic Malnutrition

The results of the T able 5 establish u n e significative relationship statistically between age children (0-59 months) and nutritional status euro the test e chi-square indicates that there is a high probability of see children less syconia i t re l badly nutrition ( $\mathrm{p}=$ 001 5). And Pelage we advance, the less we do $t$ up, and the more we develop growth retardation. Depending on the size of the household, o n e observation that rained e site many households over a significant proportion of children experiencing stunted. Indeed, $44.3 \%$ of households that had a t least 7 persons had children malnourished in overall growth retardation (RCG). But the Chi-square test was not able to prove the statistical relevance of this relationship ( $p=0,274$ ). She remained statistically in significative even when the number of children of the year exceeded 5 th household heads ( $p=0.92$ July). However, children from households under 5 ts ch year represented $43.3 \%$. The household wealth index has shown that households in the $\mathrm{P}$ rovince Kwango have fl e $\mathrm{n}$ s poor majority and that there Vait more malnourished children. A prevalence of $54.4 \%$ was found in the poor co $\mathrm{n}$ s be $26.3 \%$ among the non-poor, that is to say the average household and rich classes. The chi-square test also confirmed the fact that e t poverty could be one of the determining Principa ow s of chronic malnutrition among children from poor families ( $p=0.013$ ) (Table 5). 
Table 5: Nutritional status of children and status socio-cultural of households.

\begin{tabular}{|c|c|c|c|}
\hline \multirow{2}{*}{ Sociocultural Characteristic } & \multicolumn{3}{|c|}{ Nutritional Status } \\
\hline & RCG (\%) & Normal (\%) & Total Workforce \\
\hline $\begin{array}{l}\text { Age groups of children }{ }^{(1)} \text { : } \\
\text { - Less than } 24 \text { months } \\
-24 \text { months and over }\end{array}$ & $\begin{array}{l}31.3 \\
54.8\end{array}$ & $\begin{array}{l}66.9 \\
45.2\end{array}$ & $\begin{array}{l}160 \\
228\end{array}$ \\
\hline $\begin{array}{l}\text { Household size }{ }^{(2)} \text { : } \\
\qquad \begin{array}{l}0-7 \text { people } \\
-7 \text { people and more }\end{array}\end{array}$ & $\begin{array}{l}47.6 \\
44.3\end{array}$ & $\begin{array}{l}52.4 \\
55.7\end{array}$ & $\begin{array}{l}185 \\
203\end{array}$ \\
\hline $\begin{array}{l}\text { Number of children }{ }^{(3)} \text { : } \\
-0 \text { - } 5 \text { children } \\
-5 \text { children and more }\end{array}$ & $\begin{array}{l}43.3 \\
43.4\end{array}$ & 46.6 & 143 \\
\hline $\begin{array}{l}\text { Wealth index d u household }{ }^{(4)} \text { : } \\
\text {-Poor } \\
\text {-Middle and Rich }\end{array}$ & $\begin{array}{l}54.4 \\
26.3\end{array}$ & $\begin{array}{l}45.6 \\
73.7\end{array}$ & $\begin{array}{l}270 \\
118\end{array}$ \\
\hline
\end{tabular}

Note: Significant variable at 5\% significance level

a) $\quad \mathrm{Khi}^{2}=130,959 ; \mathrm{df}=11 ; \mathrm{p}=0,000$

b) $\quad \mathrm{Khi}^{2}=1,196 ; \mathrm{df}=11 ; \mathrm{p}=0.274$

c) $\quad \mathrm{Khi}^{2}=0.008 ; \mathrm{df}=11 ; \mathrm{p}=0.927$

d) $\quad \mathrm{Khi}^{2}=61,90 \%$; dd $=11 ; \mathrm{p}=0,013$

A correlation significative been established between the level of maternal education and nutrition of their children $(\mathrm{p}=0.000)$. Table 6 shows that malnutrition is present ch ez children whose mothers s not studied at all (47.5\%) is my least among those whose mothers are educated (43.4\%). From the point of view marital c e $\mathrm{T}$ ABLE reveals that the majority of children $\mathrm{BC}$ has experienced growth retardation when viv have in lone-parent households are of Oley's (47.8\%) ; only $45.6 \%$ of children stunted in fleetness's headed households both parent s who lived in union. However, the chi-square test could not confirm the hypothesis of $u n$ e significative relationship statistically between the nutritional status of children (0-59 months) and marital status of their mother $\mathrm{s}$ ( $\mathrm{p}=$ 0.875). Connection with the distribution of children 0-59 months by putting breast within one-hour sui $t$ vai birth and nutritional status indicates that $48.8 \%$ of e u t maln children laugh in RCG Kwango $\mathrm{n}$ were not breastfed within one hour of delivery (LAED,

for babies are. However, c ones who were put in immediately after delivery or within one hour following him had to represent $35.1 \%$. $\mathrm{P}$ e $\mathrm{r}$ tin Statistics ence this relationship has been certified by the chi-square test $(P=0.074$ ) (Table 6). None of these children lived where improved or improved water sources are used. sources that were in good condition. However, this re l a tion e etween the nutritional status of children and the source of drinking water used by the household ed n'è tai $t$ statistic lies not significant $(p=0.427$ ). Nevertheless, the relation ed statistically significant between the nutritional status of children and the quality of sanitary facilities $s(p=0.082)$. In eff e $t$, malnourished children aged 0-59 months whose households $\mathrm{n}$ 'had no hygienic latrines have re s pre-Bachelor $\mathrm{s}$ in pr side of a half (50.7\%) while those who have used ent sanitary latrines underpins not nearly one third of (30.9\%). This justifies the importance of sanitation in the success of nutrition and dietetics of children (Table 7).

2012). These e hildren did not receive colostrum is the first vaccine

Table 6: Nutritional status of children and socio-cultural status of their mothers.

\begin{tabular}{|c|c|c|c|}
\hline \multirow{2}{*}{ Sociocultural Characteristic } & \multicolumn{3}{|c|}{ Nutritional Status } \\
\hline & RCG (\%) & Normal (\%) & Total Workforce \\
\hline $\begin{array}{l}\text { Level of education of the mother }{ }^{(1)} \text { : } \\
\text { - No instructions } \\
\text { - Educated }\end{array}$ & $\begin{array}{l}47.5 \\
43.4\end{array}$ & $\begin{array}{l}57.5 \\
56.6\end{array}$ & $\begin{array}{l}236 \\
152\end{array}$ \\
\hline $\begin{array}{cl}\text { Marital status } & \text { from the mother }{ }^{(2)} \text { : } \\
& \text { - Lives alone } \\
\text { - Lives in union }\end{array}$ & $\begin{array}{l}47.8 \\
45.6\end{array}$ & 54.4 & 342 \\
\hline Mise breast childbirth ${ }^{(3)}$ : & & & \\
\hline
\end{tabular}




\begin{tabular}{|l|l|l|l|}
\hline - After the hour & 48.8 & 51.2 & 43 \\
- In the hour & 35.1 & 64.9 & 148 \\
\hline
\end{tabular}

Note: Significant variable at $5 \%$ significance level

a) $\quad \mathrm{Khi}^{2}=17.537 ; \mathrm{df}=11 ; \mathrm{p}=0,000$

b) $\quad \mathrm{Khi}^{2}=0.589 ; \mathrm{df}=11 ; \mathrm{p}=0.443$

c) $\quad \mathrm{Khi}^{2}=0.480 ; \mathrm{df}=11 ; \mathrm{p}=0.826$

Table 7: Nutritional status of small children and quality of water sources and sanitation.

\begin{tabular}{|c|c|c|c|}
\hline \multirow{2}{*}{ Source of Water and Hygiene } & \multicolumn{2}{|c|}{ Nutritional Status } \\
\cline { 2 - 4 } & RCG & Normal & Total Workforce \\
\hline Quality of drinking water sources: & 0 & 100 & 3 \\
-protected & 46.2 & 53.8 & 385 \\
-Not protected & 50.7 & 49.3 & 294 \\
\hline Hygienic latrine: & 30.9 & 69.1 & 94 \\
\hline
\end{tabular}

Note: Significant variable at $5 \%$ significance level

a) $\quad \mathrm{Khi}^{2}=0.632 ; \mathrm{ddl}=11 ; \mathrm{p}=0.427$

b) $\quad \mathrm{Khi}^{2}=3.024 ; \mathrm{ddl}=11 ; \mathrm{p}=0.082$

\section{Déterminants of Chronic Malnutrition During the Petite} this Children

The Table 8 shows clearly that the variables age, wealth index, hygienic latrine, the number of children under 5 years old in the household and level of maternal education are determining the $s$ the rain significati s $\mathrm{s}$ of chronic malnutrition among children are the Me n s 5 years in Kwango province ( $\mathrm{p} \leq 0.05$ ). These $\mathrm{r}$ e $\mathrm{n}$ t sulta nt é té validated s $99 \%$ confidence level by the test Chi-Square and nicks Log likelihood coefficients of determination, Cox and Snell and Nagelkerer (see footnote to the Table 8). Indeed, the binary logistic regression shows a hand that was how these variables determine the occurred $\mathrm{E}$ of chronic malnutrition among children 0-59 months depends of each modality in relation to the reference category what the age of the child. This indicates $99 \%$ confidence level that the more the age of the child increases, it has the chance to TRAP er chronic malnutrition ( Wald $=130.959, \mathrm{df}=1 ; \mathrm{p}=0.00$ ) . The Figure 1 shows a chance to be malnu t ri chronicle focuses on the poor and varies differently between the age of 0-23 months and 24-59 months. It is $40.5 \%$ for poor children of younger age groups (under 24 months), but for the older age groups (over 24 months) is $64.2 \%$ and higher e the critical threshold of 30\% (Chi $2=14,692$ ; $\mathrm{df}=1 ; \mathrm{p}=0.000$ ). This figure also indicates that households know s has nt poverty have $54.4 \%$ chance of having children with stunted growth while non-poor have only $26.3 \%$ chance, which is less érieur e the critical threshold of $30 \%$ ( Chi $2=26,249 ; \mathrm{df}=1 ; \mathrm{p}=$ 0.000 ). What the Logit confirms by validating the wealth index at $95 \%$ confidence level ( Wald $=6.190, \mathrm{ddl}=1 ; \mathrm{p}=0.013$ ).

Table 8: Binary logistic regression of chronic malnutrition in small children.

\begin{tabular}{|c|c|c|c|c|c|c|c|}
\hline Independent Variable & Coefficient. B & Error Type & Stat. of Wald & DOF & $\begin{array}{l}\text { S Had I L } \\
\text { If G. }\end{array}$ & $\operatorname{Exp}(B)$ & $\begin{array}{l}\text { Threshold of } \\
\text { Confidence }\end{array}$ \\
\hline Constant & $0.804^{* * *}$ & 0,165 & 23.703 & 1 & 0,000 & 2,234 & 0,99 \\
\hline Water source & $-0,003$ & 0,004 & 0,632 & 1 & 0,427 & 0,997 & \\
\hline Age of the child & $0.931^{* * *}$ & 0,081 & 130.959 & 1 & 0,000 & 2,536 & 0,99 \\
\hline Wealth index & $-0.212^{* *}$ & 0,085 & 6,190 & 1 & 0,013 & 0,809 & 0,95 \\
\hline Marital status of mothers & -0.1 & 0,130 & 0,589 & 1 & 0,443 & 0,905 & \\
\hline $\begin{array}{l}\text { Put the breasts in the time that suitable } \\
\text { childbirth }\end{array}$ & -0.027 & 0,121 & 0,048 & 1 & 0,826 & 0,974 & \\
\hline Hygienic latrine & $-0.144^{*}$ & 0,083 & 3,024 & 1 & 0,082 & 0,866 & 0,90 \\
\hline Household size & 0,102 & 0,093 & 1,196 & 1 & 0,274 & 1,107 & \\
\hline $\begin{array}{c}\text { Number of children under } 5 \text { in the } \\
\text { household }\end{array}$ & 0,009 & 0,095 & 0,008 & 1 & 0,927 & 1,009 & \\
\hline Level of education of mothers & -0.4 & 0,095 & 17.537 & 1 & 0,000 & 0,670 & 0,99 \\
\hline
\end{tabular}


Note: Analysis validated by the pseudo coefficients of determination at $5 \%$ significance level

a) $\quad \mathrm{Khi}^{2}=232,414 ; \mathrm{ddl}=11 ; \mathrm{p}=0.000$

b) 2 Log likelihood = 3979.651; R-squared of Cox and Snell $=0.067 ;$ R-squared of Nagel kerer $=0.094$

The sanitary latrines are also a determined nt $\mathrm{s}$ of growth disturbance. Indeed, non- use of sanitary latrines increased $90 \%$ $\mathrm{s}$ was $\mathrm{i}$ the co ifn year c e blessed with growth retardation (Wald $=3.024 ; \mathrm{ddl}=1 ; \mathrm{p}=0.082$ ), and that the same change has ity $\mathrm{q} u$ e the lev variable water mothers instruction (Wald $=17.537$ , $d f=1 ; p=0.000$ ). The analysis co $n$ clu $t$ that children whose mothers did not have a level of education sufficient $\mathrm{s}$ were more likely to eat foods low in nutrients and use latrines non hygienic and thus develop chronic malnutrition. Like indicates a Figure 1 to $\mathrm{u}$ t e sc are variables determining the global chronic malnutrition among children aged 0-59 months are both related to the age of the child and to the poverty of the household, children aged of at least 24 months and the household 's most poor s being in the situation the rain 's critique with the prevalence s estimated at respectively $40.5 \%$ and $64.2 \%$.

\section{Discussion of results}

Discussion on the Socio-Cultural Status of Small Children and their Mothers: Chronic malnutrition, responsible for stunting, sets in early due to causes that begin with conception until the age of two years or later in the first 1000 days of life. Children who have suffered from chronic malnutrition are left with scars for the rest of their lives. Indeed, those with stunting have compromised cognitive development, reducing their learning potential that is manifested by inadequate performance and school dropout. This e study showed that infants of e males are more vulnerable (51\%), and those whose age ranges vary entre 24 to 59 months ( $58.8 \%$ ) and live within ' household Avant more years p e tit s children under 5 years (63.1\%). A large number of little boys who have emerged in the first 1000 days of their lives run the risk of chronic malnutrition in the new province of Kwango. This risk can also be related to a medium size $\mathrm{u}$ household, who is also a d e s p factors or $\mathrm{v}$ ant influence the lives of $\mathrm{p}$ e tit $\mathrm{s}$ children. Thus, households aye not more than 7 people $(52.3 \%)$, and those where both parents viv e nt marital union $(88.1 \%)$ could in $t$ impact $t$ e $r$ on the nutritional and health status of $\mathrm{p}$ e tit s children in the household. The reason is that as their parents viv e nt union and not many children, these children may have the chance to lead a long period of reproductive life in marriage. But what about their nutritional status.

Nutritionally, the art figures are astronomical and beyond the critical threshold set by cluster Nutrition in DR C , which is $15 \%$ of households in maln u t r. So that are small children Me n s 5 years will aya nt not $\mathrm{b}$ e $\mathrm{n}$ e fited colostrum is $\mathrm{s} u$ of breast $\mathrm{s}$ maternal within one hour after delivery ( $22,5 \%$ ) and those vivr has ie nt in household already knowing the maln u t ri tion overall chronic e $(45,9 \%)$ are in need of direct humanitarian intervention in the new province of Kwango . The e breast milk is an essential source of vitamin A for infants and young children. In Fai health of lai Does breast feeding routine of our grandchildren, it would Arre t er the vicious circle of maln u tri tion, decay and underdevelopment dè is the first 1000 days .Moreover, the supply of drinking water and the use of latrine s good hygienic quality pose u $\mathrm{n} s$ érieux problem in has almost all of our households notr e new province. In fact, $99.2 \%$ of households source from unmanaged sources and $75.8 \%$ defecate in the wild for lack of a hygienic latrine . Therefore, UNICEF (201 6) says that $u$ do good hygiene and nutrition is nt the foundation of human welfare. It's favors nt optimum cognitive development and contributes nt to reduce morbidity and mortality. Indeed, from conception and through early childhood, adequate nutrition allows brain functions to develop unimpeded, and the immune system to offer the child the maximum protection. The level of instruction the mother contributes much to the ' has Mélio $r$ a tion of hygiene and health nutrition nelle small child s. A mother instrument ite may well break the cy intergenerational key malnutrition if it is well informed on the situation nutrition nelle of the child, and c el has av e c using age $\mathrm{n}$ ts extension. They play an important role in the diagnosis communautair e and the promotion of foods high in iron, storage and consumption, including some local foods, vitamin supplements and therapeutic products.

Curiously, this was not the case with the sample in our study because the index $\mathrm{r}$ ich e ss is a serious problem developing in households co ngolais. This study showed that nearly $70 \%$ of households are poor in the Kwango (Luwesi, 2018). Although they packed a similar proportion of smother s educated (68.2\%), almost half of what 's households have children knowing the maln u t ri tion chronic global e $(45,9 \%)$. This head high prevalence of chronic malnutrition is observed in almost all the provinces of the DRC and certainly has a negative impact on human capital which the country has bes oi $\mathrm{n}$ for connai be its economic emergence ( S U N 2016 Luwesi et al., 2018 ). Unfortunately, the DRC is one of only three countries, which alone accounts for $40 \%$ of all deaths of children under five. This may well influence the emergence of the Province Kwango and the country in general , and the nutritional status of future executives in this new province in particular.

Discussion on the Status of Small Children and Chronic Malnutrition: To be able to identify factors associated with chronic malnutrition in children aged 0-59 months in the province of Kwango, the $\mathrm{E}$ test $\mathrm{K}$ hi C Arré was used in order to verifier the existence of inter dependence between variables on the basis of the data of EDS RDC 2013 -2014, The analysis has established links significant between the nutritional status of children aged $0-59$ months the ur sex $(p=0.002)$, age group ( $p=0.000)$, wealth and / or poverty index $(\mathrm{p}=0.000)$, number of children under 5 in household ( $p=0.000)$, the use of $s$ latrine s hygiene $(p=0.000)$ and the setting in immediately after Bachelor delivery $(p=0.074)$. Indeed, stunting is a consequence of poor management of global 
acute malnutrition and has been reported in many studies in boys more than girls. The causes of this difference between the two sexes are not well established. E lle would perhaps due to the increased susceptibility of boys to stress. The link between the household RCG and the age group 0-23 months and 24-59 months is confirmed by the statistical classification. $\mathrm{C}$ e which means that e the end of 1000 days is a good time to assess the final outcome of the process of chronic malnutrition and the effective monitoring of actions because no preventive action is possible against stunting.

Our study also revealed that the number of children under 5 in household is a determinant of malnutrition. This is consistent with the results of the Chambers of ukuta (2003) on household food security of malnourished children to years of Kinshasa. This fl u to had found that the number of meals children depended on behalf of children in the household ber. In addition, the study conducted among preschool children in India where the number of children over 4 per family was a factor in underweight and wasting, but not in stunting. Furthermore , our e t ude has specifically targeted the high level of education of the mother. It has been reported that it predisposes her to better manage family resources, make better use of health services, have fewer children and be more attentive to the health problems of her children . With regard to the level of education, the more educated the mother, the higher the prevalence of malnutrition. In other words, the higher the mother's level of education, her preference for boys decreases. The instruction received from the mother leads to good hygiene and $p$ Enables has ux household members of Conso er the es excrement children 's $\mathrm{n}$ s poses $\mathrm{r}$ problem $\mathrm{s}$ to other members of a ns the case of gastrointestinal nematodes your $\mathrm{l} s$ that e the s roundworms and hookworms. In addition, the ingestion in large quantities of fecal bacteria by young children can lead to permanent intestinal lesions responsible for a poor absorption of nutrients, and consequently phenomena of under nutrition and rickets also known as enteropathies. environmental aspects. The 're intestinal parasites away nutrients in their favor at the expense of their absorption by the human body. This phenomenon has a long-term impact that $p$ e u t leads $r$ anemia and chronic malnutrition. That's why the small children viva $n t$ of years the $\mathrm{P}$ rovince Kwango where its $\mathrm{n}$ ' there is no enough latrine $s$ toilet $s$ are more exposed to RCG compared to children of the same slice of the age of households that use of art hygienic latrines.

6.4.3.Discussion of the Determinants of Chronic Malnutrition The recrudescence of malnutrition so acute that chronic in Province Kwango still preoccupied $\mathrm{n} \mathrm{t}$ e with the rate going beyond the emergency threshold of $10 \%$. For more than a year, more than one health zone in the Kwango has been on nutritional alert, with an average of $11.6 \%$ of children being malnourished. The prevalence of malnutrition in the $z$ ones of $s$ ant é Province of $u$ Kwango shows that the only intervention "Nutrition " has presented s are limits. It aims to manage cases of severe acute malnutrition without being associated with the activities of other sectors. It would not promote a rapid growth of small children under 5 years nor their harmonious development during the first 1000 days. What would be an obstacle to development e co no $\mathrm{m}$ ic Province. The latest Demography and Health Survey found that the proportion of children under five suffering from chronic malnutrition is increasing in the former Bandundu (32\% in 2010 and 39, $2 \%$ in 2014). The present province of Kwango ac is naked a prevalence of $45,9 \%$, exceeding lo in the national average of $15 \%$. In absolute numbers, the number of children under 5 suffering from chronic malnutrition represents more than 220,000 children.

C are astronomical figures on the prevalence of chronic malnutrition in the Kwango disclosed by the DHS-2013-2014 DRC, go often unnoticed. This is mainly due to the fact that we are not always informed and convinced of the consequences of malnutrition. Today, it is clear that inter direct nutrition ventions falls nt of the health sector , and they provide only $20 \%$ of the solution to them alone. In view of all this unpleasantness engendered chronic malnutrition among children 0 to 59 months, we felt it was important to identify the factors which promote chronic malnutrition among children aged 0 to 59 months and their association with the socio-cultural and demographic status of households with small children in Kwango Province. This would suggest in t ervent ion multisectoral order to amel iorer the nutritional status of these children. The multivariate discriminant analysis by binary logistic regression (LOGIT) retained some variables determining global chronic malnutrition in descending order. The study confirmed the link between the presence of cases of chronic malnutrition in the household with the age, poverty, the use of latrine s unhygienic, and the level of maternal education among the features socioc $\mathrm{u} l$ your $r$ they and environmental $r$ and enues in the study. It exists prevalence very high e RCG among the little one's slices age greater than 24 months and those from household's poor.

Finally, our study has verified the ' hypothesis that the lack of appropriate multisectoral strategies in the fight against certain sociocultural li e s malnutrition is the e determinant of chronic malnutrition in the province Kwango . These different ap relatives are summarized in c e basic premise of Moulna (2011) that s ousbehind our study : the differences ' ed States Nutrition tional vary according to the $\mathrm{s}$ level $\mathrm{x}$ of maternal education and are highly context of residence and socio-cultural, economic and demographic household. But for e all c es factors, key analysis assification retained only two main determinants : the household poverty score and the age range of the child . $\mathrm{C}$ es result s show sufficiently that small children from poor households that come out of the slice over 1000 days with an overall stunting see their future mortgaged . Hence the need to reflect on multisectoral mechanisms to combat chronic malnutrition. The integrated and multisectoral approach is no seu the lies necessary for the implementation of interventions to 
eradicate chronic malnutrition in $\mathrm{p}$ e tit s children but also for the economic development of the Province of Kwango.

\section{Conclusion and Recommendations}

\section{Conclusion}

Malnutrition remains a public health problem in the DRC According to EDS RDC- 2013 -2014, almost one in ten children under five suffer from wasting (8\%); almost one in two children is stunted (43\%) and one in five is underweight (23\%). In addition, one in three households is food insecure according to the results of MICS 2010. The mortality rates that have been slightly skewed over the last five years are also the highest in the world. In fact, the infant mortality rate is 58 per thousand while the infant mortality rate is 104 per thousand (EDS 2013). In Plus, in the DRC the profile analysis conducted in 2007 shows that half of all deaths are caused by malnutrition (DRC, 2014). The present study aimed to identify the main determinants of chronic malnutrition among children aged 0-59 months in Kwango Province using data from the DHS RDC-2013-2014. Statistical analysis of cross-tabulations, classification, and binary logistic regression verified the hypotheses of the following study : the determinants of chronic malnutrition in Kwango province would be due not only to the lack of appropriate multisectoral strategies in the fight against chronic malnutrition that would constitute an obstacle to community development in the province, but also the socio-cultural aspects of mothers who would not favor the growth and harmonious development of children under 5 years old during the first 1000 days because the results by classification show that children who leave the 1000-day period have a high prevalence of RCG .

Our study confirmed the link between the presence of cases of chronic malnutrition in the household with poverty ; latrine use among nutritional and environmental characteristics, age group, education level of mothers, number of children under 5 in the household. But the main determinants of the overall poor growth score of poor households, age and lack of latrine, this result further confirms the study hypothesis because classification analysis integrates chi- squared and regression . The study confirmed that there are relationships between mothers' profiles and stunted children. Ultimately, the integrated and multisectoral approach is necessary for the implementation of interventions aimed at eradicating chronic malnutrition among young children in Kwango Province considering the socio-cultural aspects of the mothers of stunted children.

\section{Recommendations}

The results obtained in this study re looking s depth sd where member ê be conducted on ground to unearth the real determinants of growth retardation in the province Kwango . That will be focalis st of underweight, the food consumption and retrospective mortality e $\mathrm{n}$ comparison with other province s DRC where malnutrition is recurrent . The A ssociation of professors u niversités the Kwango ( Panda ) can play this leading role in order to initiate research projects that can eradicate this scourge for the emergence of the province. The governm ly provincial Kwango p o ur ra and fair e a plea from the governm ly country and its development partners to obtain their involvement in the ap pui activities multisectori e is the nutrition. From me to me, it is recommended the implementation of a Provincial Multisectoral Nutrition Committee e n app l ication of D ecret Law No. 15/042 of 16 December 2015, bearing creation, and CNMN operation in DRC 's end to make nutrition a priority for the Province of Kwango. Therefore, the NGO development of where member initiate the project $s$ community s effective $s$ to $r$ edynami $s$ e $r$ Nutrition Education IYCF and other PFE, and awareness s population s against unhealthy in view of the eur mobilization in food safety (animal and plant production, latrine construction sanitary and the management of acute malnutrition in Kwango province. The NGOs of where member also identify and mentor farmers - producers of complementary foods for compliance with the proportions in the mixture of food.

\section{References}

1. Allen LH, Gillespie SR (2001) What works? A review of the efficacy and effectiveness of nutrition interventions.

2. Bendit A (2004) FRom 1989 to 2001: What did WE LEARN ABout THE "BIOLOGICAL ACTIONS OF BETA-CAROTENE". JOURNAL OF NUTRITION 134 (1): 225S-230S.

3. Bhutt ZA, Ahmad T, Blac RE (2008) For MATERnAl AND CHILD UNDERNUTRITION STUDY GROUP. WHAT WORKS? INTERVENTIONS FOR MATERNAL AND CHILD UNDERNUTRITION AND SURVIVAL 371(9610): 417440.

4. Di Luyundi TM (2013) Traditional foods and food from Bandundu in DR Congo - Directory and nutrient composition. Paris: The Harmattan, France.

5. Genevieve (2002) Proposal Booklet for the $21^{\text {st }}$ Century, Food, Nutrition, Public Policy. Montpellier: Research Unit in Nutrition, Food and Society, Institute for Research for Development (IRD), France.

6. Gentillini M, Duflo B (1992) Tropical medicine. Paris Ed Flammarion Medicine-Sciences, France.

7. SEED (2013) Knowledge Survey Attitude and Practice Mbujimayi. Kinshasa: Ministry of Planning Secretariat, DRC.

8. Kapende JK (2017) Determinants of Chronic Malnutrition to children aged 0 to 59 months in Kwango Province. "Analysis of EDS Data DRC 2013-2014". Bachelor's degree in Nutrition-Dietetics. Kenge: Medical Techniques Section, ISTM-MRP Kenge, DRC.

9. (2012) LAED, Linkages Academy for Educational Development. Facts for Feeding: Breastmilk: A critical source of vitamin for infants and young children. LAED Factsheet.

10. Luwesi CN (2018) Kenge Municipality, DRC. Proposal submitted to The Friedman School of Nutrition at Tufts University, USA and the London School of Hygiene \& Tropical Medicine, UK.

11. Meshram II, Arlappa N, Balakrishna N, Laxmaiah A, Mallikarjun Rao K, et al. (2012). Prevalence and Determinants of Undernutrition and its Trends among Pre-School Tribal Children of Maharashtra State, India. Journal of Tropical Pediatrics 58(2):125-132.

12. (2015) MINIPLAN, Ministry of Planning 2015, Multisectoral National Nutrition Plan in the DRC (PNMSN). Kinshasa: Ministry of Planning Secretariat DRC

13. (2016) MINIPLAN, Ministry of Planning. National Policy Review for the Multisectoral Approach to Nutrition in the DRC. Kinshasa: Ministry of Planning Secretariat, DRC. 
14. Moulna A (2011) Prevalence of malnutrition among children under five by gender in Chad. Professional Master's Degree in Demography. Yaoundé: IFORD, University of Yaounde II, Cameroon.

15. Mukuta N (2003) Contribution to the study of the food security of households with malnourished children in the city of Kinshasa Bachelor's degree in Nutrition-Dietetics. Kinshasa: Medical Techniques Section, ISTM-Kinshasa, DRC.

16. NAC, Nutrition at Community Assizes. 2016. Supplement feeding (4-star boiled) : Orientation manual. Kinshasa: NAC Secretariat, DRC

17. Omba BW (2001) The prevalence of kwashiorkor in Kimbanseke during early childhood. End of Cycle Graduate Work. Kinshasa: Tshangu Section CIDEP - Open University in Congo, DRC.

18. (1982) WHO, World Health Organization. Severe protein-energy malnutrition: Treatment and Therapeutics. Geneva: WHO Secretariat, Switzerland.

19. (2008) WHO, World Health Organization. Malnutrition : The starvelings. Geneva: WHO Secretariat, Switzerland.

20. (1997) WHO, UNESCO and UNICEF. Know to save. Geneva: WHO Secretariat, Switzerland.

21. Parent G (1977) Food value of edible mushrooms from Upper Shaba Region (DRC). Economic Botany, 31(4): 426-436.

22. Prasad V (2009) Should India Use Commercially Produced Ready to Use Therapeutic Foods (RUTF) for Severe Acute Malnutrition (SAM). Social Medicine 4(1)

23. (2009) PRONANUT, National Nutrition Program Survey of Knowledge, Attitudes and Practices (CAP). Kinshasa: PRONANUT Secretariat, MINISANTE , DRC.

24. (2011) PRONANUT, National Nutrition Program. Malnutrition causes infant-juvenile mortality. Kinshasa: PRONANUT Secretariat, MINISANTE, DRC.

25. (2013) PRONANUT Territorial Nutritional Surveys: Bandundu Province, 201. Kinshasa: National Nutrition Program (PRONANUT), MINISANTE DRC.

\section{ISSN: 2574-1241}

DOI: 10.26717/BJSTR.2019.18.003097

Cush Ngonzo Luwesi. Biomed J Sci \& Tech Res

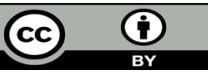

This work is licensed under Creative Commons Attribution 4.0 License

Submission Link: https://biomedres.us/submit-manuscript.php
26. (2015) PRONANUT, National Nutrition Program DRC Nutritional Surveillance, Food Security and Early Warning Newsletter. Kinshasa: PRONANUT Secretariat, MINISANTE, DRC.

27. (2016) PRONANUT, National Nutrition Program Infant and young child feeding. Kinshasa: PRONANUT Secretariat, MINISANTE, DRC

28. (2015) DRC, Democratic Republic of Congo Second Demographic and Health Survey (DHS-DRC II 2013-2014). Kinshasa: MINIPLAN and MINISANTE, DRC.

29. (2007) DRC, Democratic Republic of Congo Demographic and Health Survey (EDS-RDC I 2005-2006). Kinshasa: MINIPLAN and MINISANTE, DRC.

30. (2016) SUN, Scaling Up Nutrition Chronic Malnutrition : Mother's, Infants and Young Child's Nutrition.

31. (2017) SUSANA, Sustainable Sanitation Network for Africa. Environment, health and nutrition.

32. Triki S (2013) Prevalence and determinants of chronic malnutrition in preschool children in the city of Kenitra. Mas Memory t e $r$ Health Administration and Health. Casablanca: Hassan II University - Ain Shock, Morocco.

33. (2003) USAID, The World Bank, UNICEF, PAHO, FAO, the Micronutrient Initiative, and WHO. Anemia prevention and control : What works. Working Paper June 2003.

34. (2016) UNICEF, United Nations' Children Fund. Nutrition during the first 1000 days. Geneva: UNICEF Secretariat, Switzerland.

35. (2017) City of Kenge. Administrative Census 2017. Kenge: Town Hall of Kenge City, Kwango Province, DRC.

36. Young, H (2001) Public nutrition in emergencies: An overview of debates, dilemmas and decision-making. Disasters 23 (4): 277-291.

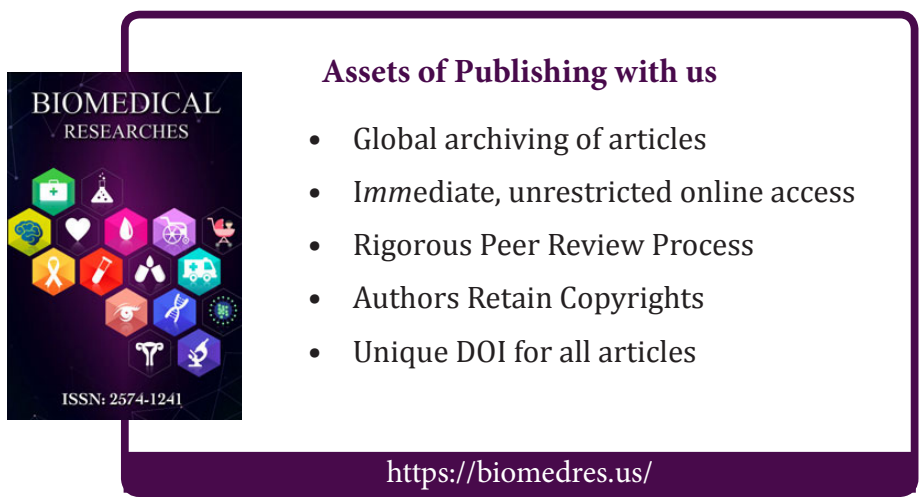

